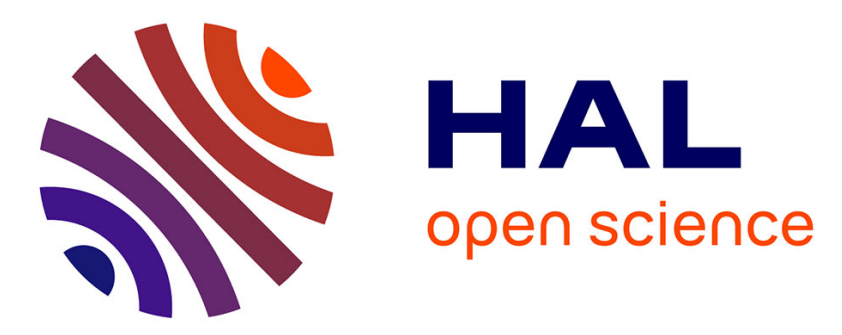

\title{
Butanethiol adsorption and dissociation on Ag (111): A periodic DFT study
}

Aixiao Li, Jean-Philip Piquemal, Johannes Richardi, Monica Calatayud

\section{To cite this version:}

Aixiao Li, Jean-Philip Piquemal, Johannes Richardi, Monica Calatayud. Butanethiol adsorption and dissociation on Ag (111): A periodic DFT study. Surface Science: A Journal Devoted to the Physics and Chemistry of Interfaces, 2016, 646, pp.247-252. 10.1016/j.susc.2015.06.009 . hal-01171804

\section{HAL Id: hal-01171804 \\ https://hal.sorbonne-universite.fr/hal-01171804}

Submitted on 6 Jul 2015

HAL is a multi-disciplinary open access archive for the deposit and dissemination of scientific research documents, whether they are published or not. The documents may come from teaching and research institutions in France or abroad, or from public or private research centers.
L'archive ouverte pluridisciplinaire HAL, est destinée au dépôt et à la diffusion de documents scientifiques de niveau recherche, publiés ou non, émanant des établissements d'enseignement et de recherche français ou étrangers, des laboratoires publics ou privés. 


\title{
Butanethiol adsorption and dissociation on Ag (111): a periodic DFT study
}

\author{
Aixiao Li Li,b,c,d $^{\mathrm{a}}$, Jean-Philip Piquemal ${ }^{\mathrm{a}, \mathrm{b}}$, Johannes Richardi ${ }^{\mathrm{c}, \mathrm{d}}$ and Monica \\ Calatayud $^{\mathrm{a}, \mathrm{b}, \mathrm{e}} *$ \\ a Sorbonne Universités, UPMC Univ Paris 06, UMR 7616, Laboratoire de Chimie Théorique, F- \\ 75005, Paris, France \\ ${ }^{\mathrm{b}}$ CNRS, UMR 7616, Laboratoire de Chimie Théorique, F-75005, Paris, France \\ c Sorbonne Universités, UPMC Univ Paris 06, UMR 7070, Laboratoire MONARIS UMR 8233, F- \\ 75005, Paris, France. \\ ${ }^{\mathrm{d}}$ CNRS, UMR 8233, Laboratoire MONARIS, F-75005, Paris, France \\ ${ }^{\mathrm{e}}$ Institut Universitaire de France, France
}

Corresponding author : Dr. M. Calatayud

Laboratoire de Chimie Théorique, Université P. M. Curie

4, Place Jussieu 75252 Paris (France)

Phone : +33144272505

Fax : +33144274117

e-mail : calatayu@1ct.jussieu.fr 


\begin{abstract}
The molecular and dissociative adsorption of butanethiol $\left(\mathrm{C}_{4} \mathrm{H}_{9} \mathrm{SH}\right)$ on regular $\mathrm{Ag}$ (111) surfaces has been studied by means of periodic ab initio density functional techniques. In molecular form, butanethiol is bound to the surface only by weak polarization-induced forces with the C-S axis tilted by $38^{\circ}$ relative to the normal surface. The $\mathrm{S}$ atom occupies a position between a hollow fcc and a bridge site. In the dissociative adsorption process, the S$\mathrm{H}$ bond breaks leading to butanethiolate. The $\mathrm{S}$ atom of the thiolate also occupies a threefold position, slightly displaced to a hollow fcc site compared to the thiol adsorption case. The C-S axis of the thiolate is tilted by about $37^{\circ}$. The calculated adsorption energies show that the butanethiol and butanethiolate have similar adsorption ability. The computed reaction pathway for the S-H dissociation gives an activation energy of $0.98 \mathrm{eV}$ indicating that the thiolate formation from thiol, although not spontaneous at room temperature, might be feasible on silver surfaces. The dissociation process induces both adsorbate and surface polarization with a significant charge transfer from the substrate to the adsorbate.
\end{abstract}

Keywords: silver, thiol, polarization, electronic structure, bond breaking 


\section{Introduction}

Understanding the structure and reactivity of interfaces is a cornerstone in modern Chemistry. The unique properties of matter of reduced size and dimensions are of outstanding importance for a variety of technological and industrial applications. Although experimental synthesis and characterization of inorganic (nano)materials is nowadays more mature than ever, theory has proven to be a critical step in their development. Modeling surfaces and interfaces has thus become crucial for the comprehension of their fundamentals, as well as for orienting experimentalists in the search of systems with controlled properties.

Silver nanoparticles are widely used for application in optoelectronic devices [1], antimicrobacterial systems [2] and heterogeneous catalysis [3, 4]. They can be obtained by chemical methods in a synthetic route involving a complex interface between water and oil [5]. In the chemical bath there are precursors, reducing agents, surfactants as well as several organic solvents. The careful choice of the reactants used and the synthesis conditions (pressure, temperature, order of addition of reactants) allow controlling the size and morphology of the nanocrystals [6-9]. In particular, the surfactant molecule used during the synthesis (or capping agent) plays a key role in the stabilization of the nanoparticles [10-12]. The surfactant is added in the final step of the synthesis to stabilize the nanocrystal surfaces and therefore plays a key role in the final shape and size of the particle. The surfactant molecule interacts primarily with the inorganic surface and the media (solvent). It is well known that strong surfactant-surface interactions block the growth of the crystal whereas weaker interactions may lead to an uncontrolled growth. Typical surfactants are alkyl chains functionalized to interact with inorganic surfaces. For instance, alkanethiols are widely used in the synthesis of silver nanoparticles [13] whereas alkaneamines are used in the synthesis of platinum nanoparticles $[14,15]$. In addition to the surfactant-surface interaction, the length of the chain is also found to play a key role in tuning their size and morphology [16]. A quantum-chemical analysis of the adsorption process between the surfactant molecule and the crystal surface will help understanding the very nature of such interface.

Surface science studies are of utmost importance to build a comprehensive picture of the molecule-surface interactions on an atomic level, in particular to understand bond formation and break as well as electronic interactions $[17,18]$. In the present paper we investigate the interaction of a model surfactant molecule, buthanethiol, with Ag (111) termination by means of periodic state of the art quantum chemical tools. This simplified model will shed light on the geometrical and electronic effects of the surfactant-surface system on a molecular level. These results will be the basis for the development of more complex models aiming at representing inorganic nanoparticles in realistic conditions, in particular particles of nanoscopic dimensions with a well-defined size and their interaction with solvent and surfactant.

We study the Ag (111) surface since it is the most stable for the cubic face centered silver bulk structure. The geometry and adsorption properties of this termination are extensively reported in the literature both from experimental and theoretical works, see for instance ref. 
[19]. Experimental works report the stability of a reconstructed $(\sqrt{ } 7 \times \sqrt{ } 7) \mathrm{R} 19^{\circ}$ pattern upon adsorption of sulfur [20], methanethiol [21] or pentanethiol [22] on Ag (111). Yu et al. [20-22] report a near-hexagonal Ag surface layer with reduced atomic density so that it is a $3 / 7$ of the underlying substrate layer and the adsorbed thiol occupy three different sites on the surface $\sqrt{7} \times \sqrt{7}$ unit cell. Short alkane chains may also lead to $\sqrt{ } 3 \times \sqrt{3}$ R30 and p2x2 patterns [23]. Theoretical works have shown that both reconstructed and unreconstructed silver substrate possess similar energy and might thus be of similar stability in the adsorption of methanethiolate [24]. Also, the reconstruction of the $\operatorname{Ag}(111)$ in the presence of sulfur atoms has been investigated by density functional theory (DFT) [25]. The stability of self-assembled monolayers has also been addressed by classical methods [26-28]. We will focus our study on the regular (111) termination in order to gain understanding on the geometrical and electronic effects taking place upon adsorption, we restrict our investigation to low coverage $\theta=1 / 7$ to mimic the early stages of adsorption. Future works will address more reactive models.

The paper is organized as follows: in section 2, the computational procedures used are described together with the models used. In section 3, results are presented and discussed as regards geometry, energetics, reactivity and electronic structure of the dissociation process. A conclusion section closes the paper.

\section{Methods and models}

The calculations carried out are based on density functional theory DFT as implemented in the Vienna ab initio simulation package VASP [29-30]. The one-electron Kohn-Sham orbitals are developed by using a plane wave basis set and the interaction with the atomic cores is described through the projector augmented-wave pseudopotential (PAW) [31-32]. The PAW method achieves a high accuracy at a relatively modest cut-off energy of $400 \mathrm{eV}$. Electronic exchange and correlation are described by the optPBE functional that also accounts for dispersion interactions $[33,34,35,36]$. Calculations were spin unpolarized. The self-consistency cycle was terminated when the total energies in the next step only changed by less than $10^{-6} \mathrm{eV}$ per cell. Brillouin-zone integrations were performed on Monkhorst-Pack grids [37] adapted to the size of the supercell with distance between k-points $\sim 0.05 \AA^{-1}$.

The metallic substrates were modeled by periodically repeated five-layer slabs with a vertical extension of the supercell of $45 \AA$ to ensure a minimum separation of $25 \AA$ between the top of the adsorbed molecule and the bottom of the periodically repeated slab. Molecules were adsorbed on one side of the slab only, the other side being a clean metal surface, and dipole corrections are introduced in the calculation to prevent artificial polarization.

The geometry optimizations were carried out with the conjugate gradient algorithm until all forces on the atoms are converged to $\mathrm{F} \leq 0.1 \mathrm{eV} \AA^{-1}$. The ionic relaxation energies were converged to $10^{-4} \mathrm{eV}$. The adsorbates and three uppermost slab layers are fully relaxed, the two bottom slab layers are kept fixed to optimized bulk positions. For adsorption energy calculations, a gas-phase butanethiol molecule is calculated in a box of dimensions $20 \times 20 \times 20$ $\AA^{3}$. 
For assessing the role of Van der Waals interactions, the calculations are performed using the optPBE functional and the comparisons are made with the PBE [38] and the semiempirical Grimme D2 $[39,40]$ method for the bulk Ag, see supporting information Table $\mathrm{S} 1$. The convergence of the bulk parameters with respect to the k-points set is also reported in supporting information, Table S2. The optPBE method performs well for bulk and has shown to describe properly metallic surfaces [41], for this reason we chose optPBE for our study.

We have also determined the barrier for the dehydrogenation of adsorbed butanethiol to co-adsorbed butanethiolate and atomic hydrogen. The transition state search was performed using the Nudged Elastic Band (NEB) method [42]. In our calculation, 4 intermediate images were created and minimized roughly, the $\mathrm{S}-\mathrm{H}$ and closest neighbors were allowed to relax. The one with the highest energy was treated as initial guess by the dimer method [43]. A frequency analysis of the transition state is carried out to check the presence of only one imaginary frequency. The structures for initial, transition and final states are given in the Supplementary material.

The thiol chosen as the model is butanethiol (see Figure 1, left) because it is large enough to be considered as a potential initiator of self-assembled monolayers [44], and small enough to perform state-of-art periodic DFT calculations on the system.

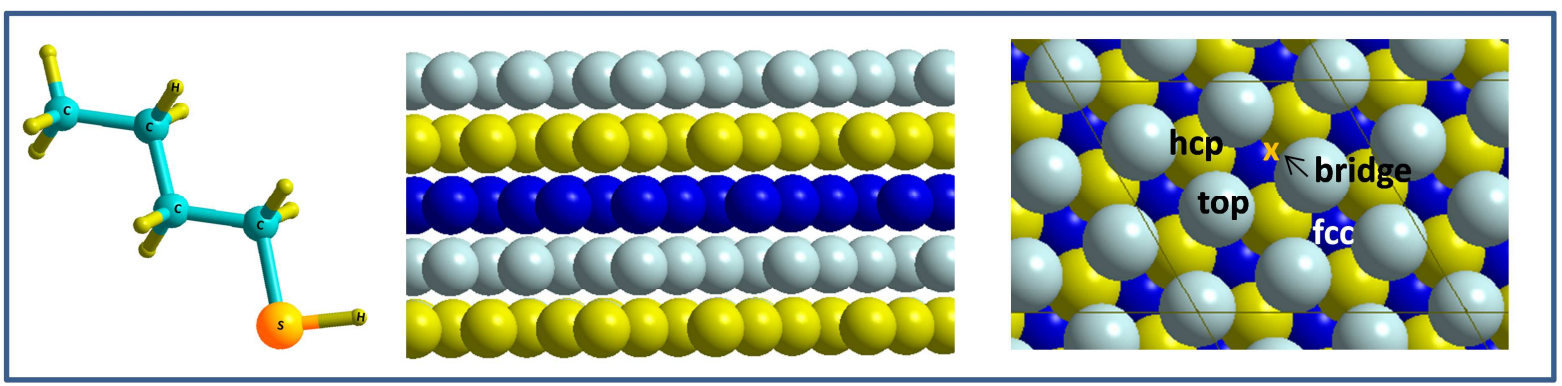

Figure 1. Left: gas-phase butanethiol molecule. Middle: side view of the metallic (111) slab used in the calculations. Right: top view of the slab used with the potential adsorption sites of butanethiol (top, bridge, hollow fcc and hollow hcp). The $\sqrt{ } 7 \times \sqrt{ } 7$ cell is displayed. The first and fourth layers are colored in grey, second and fifth layers are colored in yellow, and the third layer is colored in blue.

The geometrical parameters obtained after optimization in the gas phase model are given in Table 1. We also optimized the molecular geometry using the GAUSSIAN09 suite of programs [45], at the MP2 level of theory with the 6-311++g(3df,2pd) basis set. Indeed, it has been shown that MP2 calculations are in perfect agreement with experimental values [46] [47]. Our VASP calculation results are consistent with the MP2 ones.

\begin{tabular}{|c|c|c|c|c|c|}
\hline & & & $\begin{array}{c}\text { adsorbed } \\
\mathrm{C}_{4} \mathrm{H}_{9} \mathrm{SH}\end{array}$ & $\begin{array}{l}\text { adsorbed } \\
\mathrm{C}_{4} \mathrm{H}_{9} \mathrm{SH}(\ddagger)\end{array}$ & $\begin{array}{l}\text { adsorbed } \\
\mathrm{C}_{4} \mathrm{H}_{9} \mathrm{~S}\end{array}$ \\
\hline Bond $(\AA)$ & VASP & MP2 & VASP & VASP & VASP \\
\hline $\mathrm{C}-\mathrm{S}$ & 1.84 & 1.82 & 1.85 & 1.85 & 1.86 \\
\hline S-H & 1.35 & 1.33 & 1.35 & 1.36 & - \\
\hline
\end{tabular}




\begin{tabular}{|lccclc|}
\hline $\mathrm{C}_{1}-\mathrm{C}_{2}$ & 1.53 & 1.52 & 1.54 & 1.53 & 1.53 \\
$\mathrm{C}_{1}-\mathrm{H}$ & 1.10 & 1.09 & 1.11 & 1.10 & 1.10 \\
\hline Angle (o) & \multicolumn{7}{c}{} & & & \\
\hline $\mathrm{H}-\mathrm{S}-\mathrm{C}_{1}$ & 96.67 & 97.30 & 97.20 & 97.91 & - \\
$\mathrm{S}-\mathrm{C}_{1}-\mathrm{C}_{2}$ & 110.07 & 108.78 & 110.12 & 108.16 & 109.97 \\
$\mathrm{C}_{1}-\mathrm{C}_{2}-\mathrm{C}_{3}$ & 112.42 & 111.93 & 111.42 & 111.51 & 113.22 \\
\hline
\end{tabular}

Table 1. isolated butanethiol structure parameters from both VASP and Gaussian 09 calculations, also structure parameters of both butanethiol and butane thiolate in complex state from VASP calculations. $\ddagger$ means transition state.

\section{Results and discussion}

We studied the adsorption of one butanethiol molecule on a $\sqrt{7} \times \sqrt{7}$ periodic cell shown in Figure 1. To find the equilibrium configuration, we have used different starting geometries, with the $\mathrm{S}$ atom of the molecule initially placed above a silver atom (ontop), into a bridge site or into a fcc or hcp hollow site. Since the adsorption can take place in two different ways, molecular or dissociated, we have investigated these two possibilities.

\subsection{Molecular adsorption}

$$
N \mathrm{C}_{4} \mathrm{H}_{9}-\mathrm{SH}(\mathrm{g})+\mathrm{Ag}(\text { clean }) \rightarrow \quad N \mathrm{C}_{4} \mathrm{H}_{9}-\mathrm{SH} \cdot \mathrm{Ag}(\mathrm{slab})
$$

The adsorption energy per molecule $\left(\mathrm{E}_{\mathrm{ads}}\right)$ is the difference between the total energy of the slab with the adsorbed molecule $\left(E_{\text {slab}}\right)$ and the sum of the total energies of the subsystems, i.e., the clean metal surface in its equilibrium structure $\left(\mathrm{E}_{\text {clean }}\right)$ and an isolated butanethiol $\left(\mathrm{E}_{\mathrm{mol}}\right)$.

$$
\mathrm{E}_{\mathrm{ads}}=\left[\mathrm{E}_{\mathrm{slab}}-\mathrm{E}_{\text {clean }}-N \mathrm{E}_{\mathrm{mol}}\right] / N
$$

Note that the sign of $E_{a d s}$ is chosen such that a negative number means that the energy of the system decreases upon adsorption. Table 2 shows the calculated adsorption energy $E_{\text {ads. }}$ The most favorable mode, $-0.46 \mathrm{eV}$, is found for a mixed hollow fcc-bridge position obtained from the spontaneous migration of the molecule from an ontop position. The starting geometry of the molecule on fcc and bridging sites moves during optimization closer to a less symmetric position, as shown in Figure 2a. They lead to hollow-bridge positions as the most favorable adsorption sites. The geometry parameters of the thiol are listed in Table 1 . We found that the bond lengths do not change compared to the isolated thiol, as well as the angles. The molecule is tilted 38 degrees with respect to the surface normal.

\begin{tabular}{|c|l|l|l|l|}
\hline & \multicolumn{2}{|c|}{ Molecular adsorption } & \multicolumn{2}{l|}{ Dissociative adsorption } \\
\hline Initial site & $\mathrm{E}_{\mathrm{ads}}$ & $\begin{array}{l}\text { Final site } \\
\text { (optimized) }\end{array}$ & $\mathrm{E}_{\mathrm{ads}}$ & $\begin{array}{l}\text { Final site } \\
\text { (optimized) }\end{array}$ \\
\hline
\end{tabular}




\begin{tabular}{|l|l|l|l|l|}
\hline Ontop & -0.46 & $\begin{array}{l}\text { Between hollow fcc } \\
\text { and bridge }\end{array}$ & -0.52 & around hollow fcc \\
\hline bridge & -0.31 & bridge & -0.29 & $\begin{array}{l}\text { around bridge and } \\
\text { hollow hcp }\end{array}$ \\
\hline Hollow fcc & -0.30 & Hollow fcc & -0.28 & around bridge \\
\hline Hollow hcp & 0.16 & Hollow hcp & -0.27 & around hollow hcp \\
\hline
\end{tabular}

Table 2: Calculated adsorption energy in $\mathrm{eV}$ for different surface sites, for both molecular and dissociative adsorption. The final optimized positions of the butanethiol/butanethiolate are also listed.

\subsection{Dissociative adsorption.}

$$
N \mathrm{C}_{4} \mathrm{H}_{9} \mathrm{~S}-\mathrm{H}(\mathrm{g})+\mathrm{Ag}(\text { clean }) \quad \rightarrow \quad N \mathrm{C}_{4} \mathrm{H}_{9} \mathrm{~S}-\mathrm{Ag}(\mathrm{slab})+N \mathrm{H} \text { (ads) }
$$

As mentioned above, besides the molecular adsorption, there is also a dissociative mechanism possible, with the $\mathrm{S}-\mathrm{H}$ bond cleavage. The thiolate moiety adsorbs at a position around the hollow fcc site, whereas the hydrogen is put on a hollow fcc position neighboring the thiolate. Atomic hydrogen is reported to adsorb on fcc sites for most (111) metallic surfaces [19]. The geometry of the most stable structure obtained is displayed in Figure 2c $(\mathrm{RS}+\mathrm{H})$. Table 2 shows the adsorption energy obtained for the butanethiolate adsorption. It can be seen that butanethiolate has clear preference for the fcc sites.

The geometry parameters of the thiolate are listed in Table 1, we found that the bond lengths do not change compared to the molecular absorbed thiol, the angles change slightly, $1.80^{\circ}$ for C-C-C angle for example. The molecule is tilted 37 degrees with respect to the surface normal.

The distance to the Ag surface is significantly reduced as compared to the thiol molecular adsorption, indicating a more efficient bonding. This is evidenced by Table 3, where the distance between the $\mathrm{S}$ atom and the three closest $\mathrm{Ag}$ atoms is given. Note that the $\mathrm{Ag}$ atoms close to the sulfur atoms slightly move upon adsorption in both cases. 


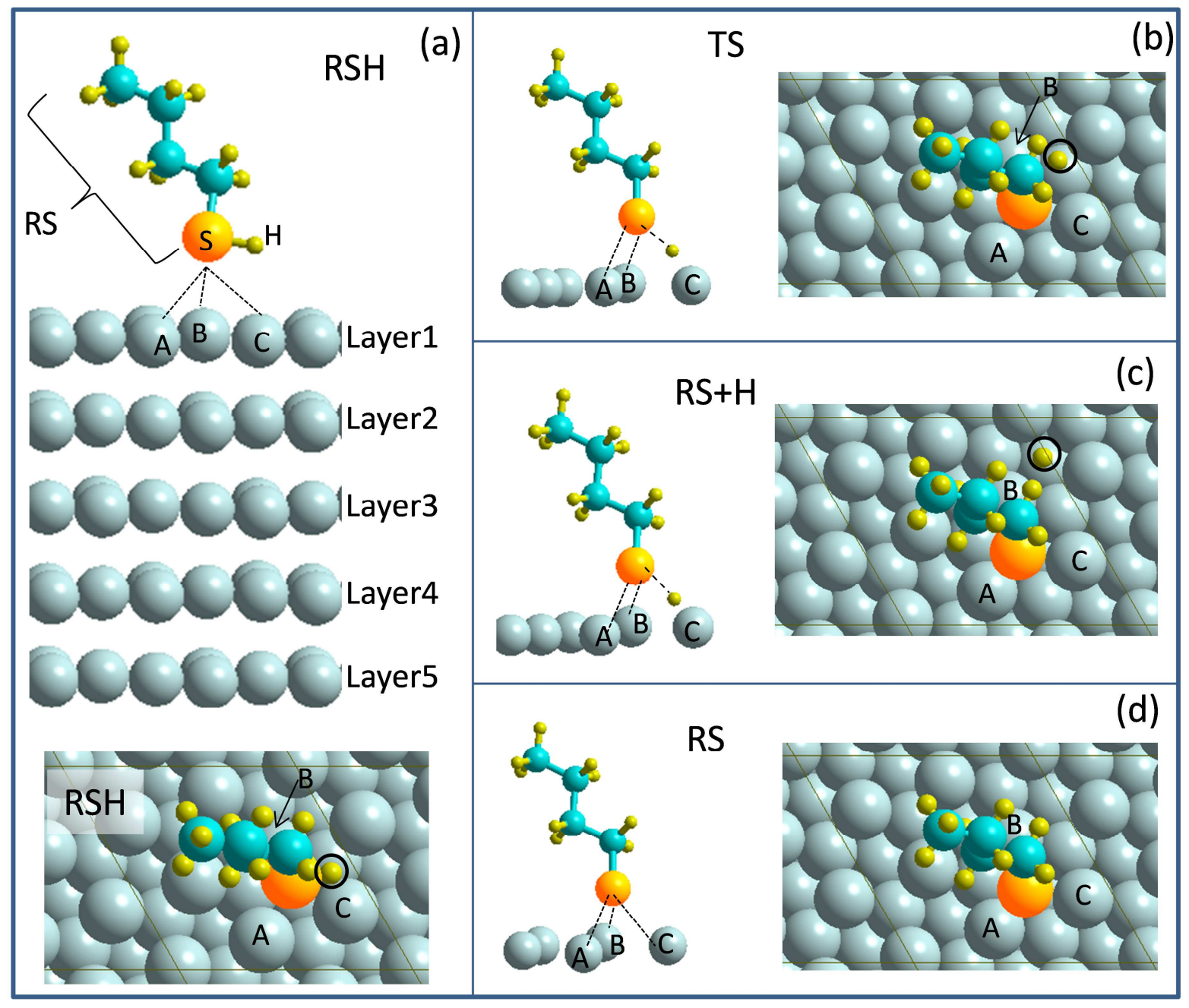

Figure 2: The most stable adsorption geometries for the systems calculated, side and top views. Black circles show the hydrogen of the $\mathrm{SH}$ group. Sites A, B, C are surface sites (a). The favorable $\mathrm{C}_{4} \mathrm{SH}$ adsorption site for the molecular adsorption mode RSH. (b) The transition state TS. (c) Dissociated product with $\mathrm{H}$ adsorbed RS $+\mathrm{H}$ (d) dissociated product RS without coadsorbed $\mathrm{H}$.

\begin{tabular}{|c|c|c|c|c|}
\hline & \multicolumn{4}{|c|}{$\mathrm{d}_{\mathrm{S}-\mathrm{Ag}}$} \\
\hline Silver atom & $\mathrm{RSH}$ & $\mathrm{TS}$ & $\mathrm{RS}+\mathrm{H}$ & $\mathrm{RS}$ \\
\hline $\mathrm{Ag}(\mathrm{A})$ & $3.61 \AA$ & $3.04 \AA$ & $2.70 \AA$ & $2.59 \AA$ \\
\hline $\mathrm{Ag}(\mathrm{B})$ & $2.94 \AA$ & $2.64 \AA$ & $2.59 \AA$ & $2.70 \AA$ \\
\hline $\mathrm{Ag}(\mathrm{C})$ & $3.55 \AA$ & $3.05 \AA$ & $2.75 \AA$ & $2.74 \AA$ \\
\hline
\end{tabular}

Table 3. Distances between sulfur of thiol/thiolate to the three Ag atoms labelled in Figure 2. 
An analysis of Table 2 shows that the molecular and dissociative adsorption modes are close in energy. Even if a small preference seems to appear for the dissociative adsorption, $-0.46 \mathrm{eV}$ (molecular) vs. $-0.52 \mathrm{eV}$ (dissociated), the two modes may coexist on the surface. In order to gain further understanding on the dissociation mechanism we have computed the energetic barrier of a reaction path for the dissociation of thiol to thiolate discussed in section 3.3.

\subsection{Dissociation path from thiol to thiolate}

Even though in gas phase the dissociation of thiols to thiolates is an endothermic process, experiments show that dissociation of thiols to thiolates can take place on transitionmetal surfaces. The dissociation on transition metal surfaces is caused by the interaction of the sulfur atom with the support, which competes in strength with the S-H bond. We have studied the process of the butanethiol dissociation on $\mathrm{Ag}(111)(\sqrt{7} \times \sqrt{7}) \mathrm{R} 19.1$ cell. Figures 2 and 3 display the structures of the starting point (molecular RSH), the transition state (TS) and dissociated product (thiolate+adsorbed $\mathrm{H}, \mathrm{RS}+\mathrm{H}$ ).

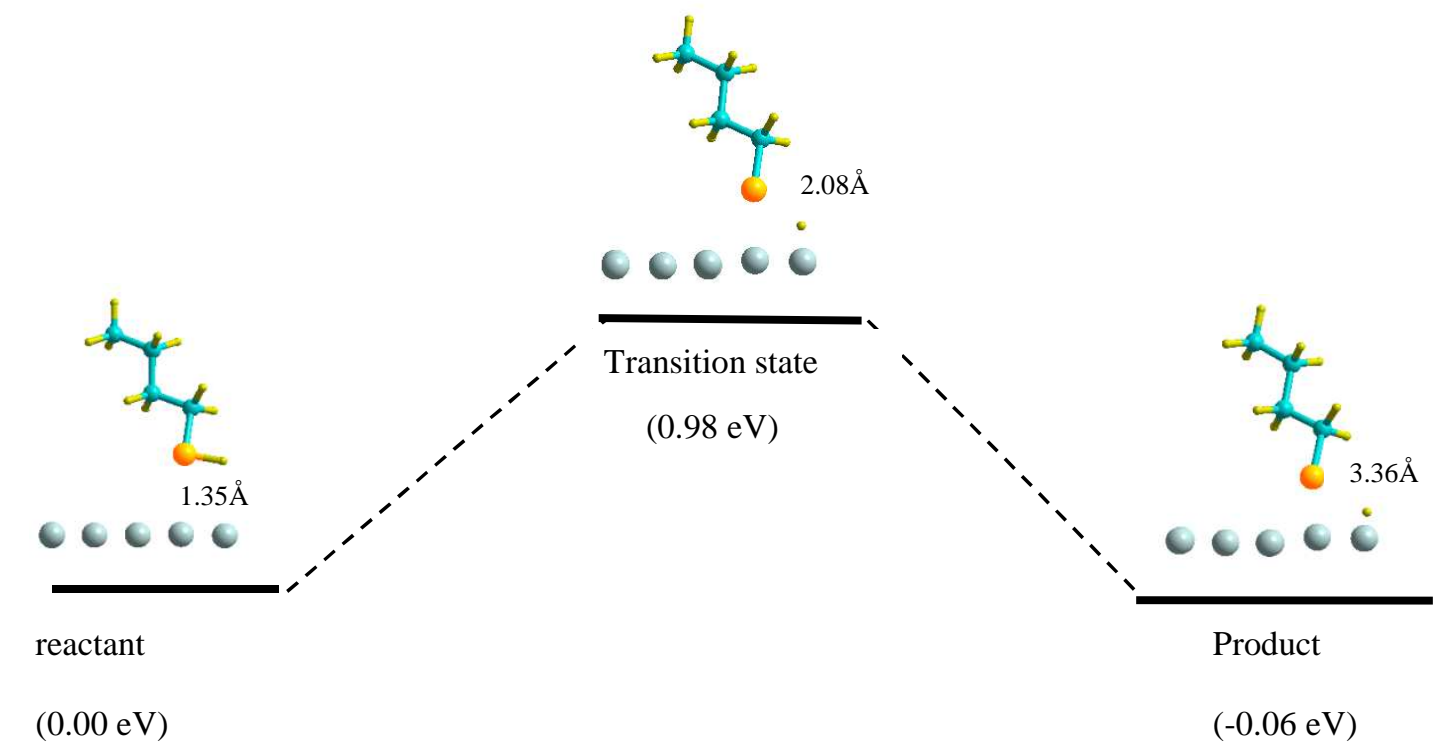

Figure 3. Reaction path for the dissociation of butanethiol to butanethiolate (energy relative to the initial structure, in eV, S-H distances are indicated in $\AA$ ).

For the reaction path studied, the butanethiol is initially molecularly adsorbed between hollow fcc and bridge sites. In the transition state the molecule moves closer to the hollow fcc position and the $\mathrm{H}$ atom moves close to a hollow hcp position. The activation energy in the transition state is $0.98 \mathrm{eV} /$ molecule and the $\mathrm{S}-\mathrm{H}$ bond is stretched by $0.73 \AA$. To confirm the nature of the transition state, the analysis of the vibrational eigenmodes on the $\mathrm{S}-\mathrm{H}$ bond has also been performed. All eigenstates except the S-H stretching mode have real eigenvalues, thus confirming the first-order saddle point of the transition structure. To reach the final coadsorption state, the hydrogen atom moves to the neighboring hollow fcc position. The 
reaction is exothermic by $0.06 \mathrm{eV}$. This is not a huge amount of energy and indicates that the two species, thiol and thiolate, may coexist on the surface. The energy barrier, $0.98 \mathrm{eV}$ (as shown in Figure 3), does not support spontaneous dissociation at room temperature on $\mathrm{Ag}(111)$. However, the dissociation of thiol to form thiolate can be favored by other routes i) the presence of more reactive surfaces, like the (001) surface, and / or defects, expected to be numerous in a real nanoparticle. ii) if the adsorbed $\mathrm{H}$ diffuse and recombine to desorb as $\mathrm{H}_{2}$, the dissociation reaction would favor the formation of thiolates following equation (4):

$$
N \mathrm{C}_{4} \mathrm{H}_{9} \mathrm{~S}-\mathrm{H}(\mathrm{g})+\mathrm{Ag}(\text { clean }) \quad \rightarrow \quad N \mathrm{C}_{4} \mathrm{H}_{9} \mathrm{~S}-\mathrm{Ag}(\mathrm{slab})+N / 2 \mathrm{H}_{2}(\mathrm{~g})
$$

The formation of $\mathrm{H}_{2}$ is thermodynamically favorable, the energetic balance of eq. (4) is -0.25 $\mathrm{eV}$. This means that desorption of $\mathrm{H}_{2}$ stabilizes the thiolate form. Moreover, the release of $\mathrm{H}_{2}$ contributes entropically to favor products in eq. (4), and is in principle irreversible if the synthesis is done in open vessels. The structure of the thiolate without neighboring hydrogen is very close to that of the thiolate with hydrogen, see Figure $2 \mathrm{~d}$ (RS). Concerning the route i) in the case of gold reconstructed surface [48], the S-H dissociation takes place through a transition state of $0.32 \mathrm{eV}$. For methanethiol dense adsorption $(\sqrt{3} \times \sqrt{3}$ R30 pattern) DFT calculations [46] give no barrier for $\mathrm{Ni}, 0.18 \mathrm{eV}$ for $\mathrm{Pd}$ and $0.61 \mathrm{eV}$ for Pt. It is thus expected that in the case of silver, higher coverage and irregular surfaces lead to a barrier lower than $0.98 \mathrm{eV}$ making dissociation easier.

\subsection{Electronic structure description}

The electronic structure of the adsorbed molecules has been studied by means of Bader's analysis [49]. The charge enclosed within the Bader volume is a good approximation to the total electronic charge of an atom and allows tracking charge transfer phenomena upon adsorption. Bader charge distribution can also be used to determine multipole moments of interacting atoms or molecules $[50,51]$.

The Bader charges were calculated for the adsorption systems as well as for the isolated molecule and slab. The charges of several important atoms for adsorption are listed in Table 4, the charge condensed on each atom is reported as supplementary material. An analysis of the data shows that in the case of the molecular adsorption RSH there is no significant charge transfer between the molecule and the slab: the molecule (without the hydrogen atom) is charged only $0.024 \mathrm{ee}$ and the slab $-0.018 \mathrm{e} \mid$; the hydrogen atom is almost neutral $-0.005|\mathrm{e}|$. The adsorption might be promoted by polarization induced forces as suggested in ref [52]. A different picture is observed for the dissociated systems. The product of dissociation (thiolate neighboring hydrogen, $\mathrm{RS}+\mathrm{H}$ ) is charged $-0.332 \mathrm{e} \mid$ and the slab becomes positively charged by $0.541 \mathrm{el}$. In this case, the dissociated hydrogen becomes also negatively charged, $-0.209|\mathrm{e}|$ and can be described as a surface hydride. Upon removal of such hydrogen sites, the system RS still possesses a thiolate charged $-0.334|\mathrm{e}|$ and the slab is charged $+0.334|\mathrm{e}|$. The sulfur charge changes from $-0.023 \mathrm{e} \mid$ in the gas phase to $-0.031|\mathrm{e}|$ for the molecular adsorption, $-0.403|\mathrm{e}|$ for the $\mathrm{RS}+\mathrm{H}$ and $-0.399|\mathrm{e}|$ for the RS systems. The electronic structure of the transition state is intermediate between reactant and product and 
closer to the latter meaning that it is a late transition state. We conclude that the dissociation of the thiol on the surface dramatically perturbs the electronic distribution and induces a significant charge transfer from the silver surface to the thiolate moiety. Additionally the presence of surface hydrogen increases the charge transfer from the surface.

In order to analyze the electronic structure of the surface we have reported the charges on the $\mathrm{Ag}$ atoms close to the sulfur atom. They are slightly negative, around $-0.02|\mathrm{e}|$ in the bare slab and reach values around $0.08 \mathrm{el}$ in the thiolate species. The distribution of charge is not homogeneous within the slab, the closer to the sulfur atom the higher the positive charge of the silver atoms. In the presence of atomic hydrogen the charge reaches values of $0.145|\mathrm{e}|$ (atom $\mathrm{Ag}_{\mathrm{B}}$ in $\mathrm{RS}+\mathrm{H}$ ). Interestingly, the charge is distributed in layers in the slab. Table 4 shows the average charge for each layer together with the standard deviation in parentheses. The bare slab shows an alternance of charge -0.019/0.019/-0.001 |e|. Upon molecular adsorption of the thiol, the distribution is only slightly perturbed: $-0.020 / 0.018 /-0.01 \mathrm{el}$. The thiolate RS+H system shows the largest change in slab charge distribution: 0.452/0.100/0.002 e| meaning that the slab is polarized in the presence of thiolate and hydride species. In the absence of hydride, RS system, the same trend is observed although the values of the charge are smaller: 0.224/0.117/0.004 |e|. The standard deviation is a measure of the distribution of charge in the layer. Table 4 displays the larger values for standard deviation found for the first slab layer indicating that the presence of the adsorbate induces an inhomogeneous redistribution of the charge among the different silver atoms. In particular, thiolate species exhibit larger values than thiol $(0.046 \mathrm{e} \mid$ and $0.024 \mathrm{e} \mid$ respectively) which is consistent with the larger perturbation observed in the surface sites charge. Both the average charge and standard deviation decrease for the second layer and is found negligible in the third layer, indicating a stronger polarization effect in the external slab atoms as expected from their proximity to the adsorbate.

\begin{tabular}{|l|c|l|l|l|l|l|}
\hline & $\begin{array}{l}\text { Gas-phase } \\
\text { thiol }\end{array}$ & Ag slab & Thiol RSH & TS & $\begin{array}{l}\text { Thiolate } \\
\text { RS+H }\end{array}$ & Thiolate RS \\
\hline RS & 0.024 & - & 0.024 & -0.265 & -0.332 & -0.334 \\
\hline $\mathrm{S}$ & -0.023 & - & -0.031 & -0.323 & -0.403 & -0.399 \\
\hline $\mathrm{H}$ & -0.024 & - & -0.005 & -0.057 & -0.209 & - \\
\hline slab & - & 0.000 & -0.018 & 0.322 & 0.541 & 0.334 \\
\hline Ag A & - & -0.018 & -0.012 & 0.039 & 0.081 & 0.082 \\
\hline Ag B & - & -0.019 & 0.036 & 0.107 & 0.145 & 0.070 \\
\hline Ag C & - & -0.020 & -0.029 & 0.075 & 0.081 & 0.083 \\
\hline Layer1 & - & $-0.019(0.001)$ & $-0.020(0.024)$ & $0.210(0.043)$ & $0.452(0.046)$ & $0.224(0.041)$ \\
\hline Layer2 & - & $0.019(0.000)$ & $0.018(0.002)$ & $0.116(0.005)$ & $0.100(0.005)$ & $0.117(0.006)$ \\
\hline Layer3 & - & $-0.002(0.000)$ & $-0.001(0.001)$ & $0.007(0.003)$ & $0.002(0.003)$ & $0.004(0.003)$ \\
\hline
\end{tabular}

Table 4. Bader charges in |e| for selected atoms in adsorption systems. The Ag A/B/C atoms are shown in Figure 2. The average values per slab layer are shown (in parentheses the standard deviation). Labelling as in Figure 2.

The density of states has also been calculated to follow the S-H dissociation reaction. Figure 4 displays the total and atom-projected density of states for reactant $\mathrm{RSH}$, transition state TS, 
product $\mathrm{RS}+\mathrm{H}$ and thiolate $\mathrm{RS}$ after $\mathrm{H}$ desorption. The slab contribution is a band between -3 and $-7 \mathrm{eV}$, corresponding to the $\mathrm{Ag} \mathrm{d}$ states, and a wide band between -2 and $6 \mathrm{eV}$ corresponding to Ag s states, partially occupied and thus of metallic character. The presence of the molecular thiol on the silver surface is characterized by a molecular state 2-3 eV below the Fermi level, mainly associated to the $\mathrm{S}$ atom at $-2.2 \mathrm{eV}$, and a set of bands at 4-6 eV below the Fermi level, which contains the $\mathrm{H}$ contribution at $-5 \mathrm{eV}$. The molecular virtual states are located 1.5-6 eV above the Fermi level. The elongation of the S-H bond to form the transition state leads to broadening of the bands due to the interaction between slab and molecule. Besides, the $\mathrm{S}$ level shifts to higher energies, $-1.8 \mathrm{eV}$, and the gap between $\mathrm{H}$ occupied and unoccupied levels is lowered: a state is located at $-2.2 \mathrm{eV}$ and a wide band centered at $\sim 2 \mathrm{eV}$. The product $\mathrm{RS}+\mathrm{H}$ is characterized by the thiolate $\mathrm{S}$ level at $-1.8 \mathrm{eV}$ and a single $\mathrm{H}$ band spread between -2.2 and $2 \mathrm{eV}$, that comes from the merging of the TS levels; close in energy a second band from 2 to $6 \mathrm{eV}$ is found almost overlapping with the former. Such structure corresponds to the presence of a hydride species since the $\mathrm{H} s$ states become occupied. The removal of the $\mathrm{H}$ atom from the slab does not alter the thiolate $(\mathrm{S})$ electronic structure. It can be observed that the electronic structure of the TS is closer to the product than to the reactant. This picture is fully coherent with the Bader analysis and with previous analysis in the literature describing S-H dissociation on and gold surfaces [24] and L-cysteine adsorption on silver [53]. 

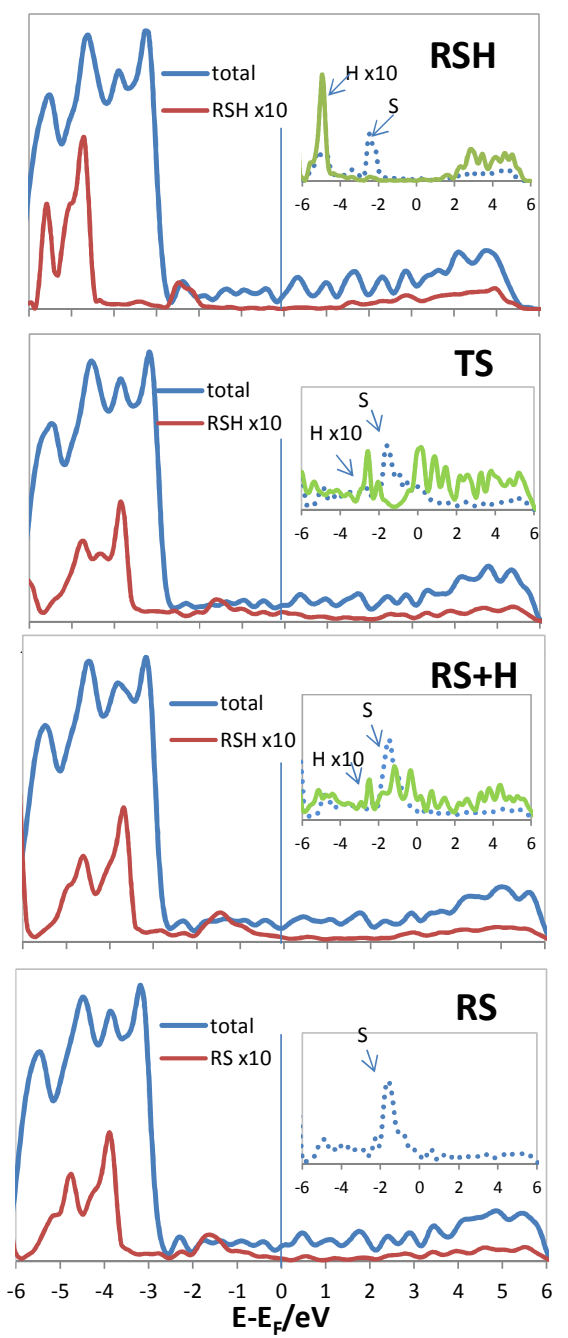

Figure 4: Density of states for the structures involved in the SH dissociation, in arbitrary units. Inset: contribution of $\mathrm{H}$ and $\mathrm{S}$ atoms.

\section{Conclusion}

To understand the molecular and dissociative adsorption of butanethiol on the $\mathrm{Ag}$ (111) surface, vdw-DFT calculations are performed. The molecular adsorption does not lead to important elongation of the $\mathrm{C}-\mathrm{S}$ and $\mathrm{S}-\mathrm{H}$ bonds. The fully relaxed equilibrium configurations show that the $\mathrm{S}$ atom locates between a hollow and a bridge site. In the dissociative adsorption process, the $\mathrm{S}$ atoms as well as the atomic hydrogen locate on hollow fcc positions. The adsorption energies for the most stable adsorption sites are $-0.46 \mathrm{eV}$ and $0.52 \mathrm{eV}$ for butanethiol and butanethiolate, respectively. The activation energy for the S-H dissociation has been calculated to be $0.98 \mathrm{eV}$. The removal of surface hydrogen would favor the stabilization of thiolate species. The dissociation of the thiol S-H bond leads to charge transfer to the adsorbates resulting in the polarization of the slab. Future works will investigate more complex systems such as higher coverage and surface reconstruction. 


\section{Acknowledgements}

This work was performed using HPC resources from GENCI- CINES/IDRIS (Grant 2014x2014082131, 2015- x2015082131, 2014- x2014086946) and the CCRE-DSI of Universite P. M. Curie. This work has been funded by MiChem French Labex (AL). Dr. F. Tielens is warmly acknowledged for stimulating discussion. MC thanks Dr. B. Diawara for the visualization program Modelview.

\section{References}

[1] K. Lu, N. Manjooran, M. Radovic, E. Medvedovski, E.A. Olevsky, C. Li, G. Singh, N. Chopra, G. Pickrell, Advances in nanomaterials and nanostructures, 2292011.

[2] M. Epple Chernousova, Angew Chem. Int. Ed. 52 (2013) 1636-1653.

[3] C. Wen, A. Yin, W.-L. Dai, Appl. Catal. B Environ. 160-161 (2014) 730.

[4] D.P. Debecker, C. Faure, M.E. Meyre, A. Derre, E.M. Gaigneaux, Small 4 (2008) 2096-2096.

[5] W. Zhang, X. Qiao, J. Chen, Mater. Sci. Eng. B 142 (2007) 1-15.

[6] B. Wiley, Y. Sun, Y. Xia, Acc. Chem. Res. 40 (2007) 1067.

[7] N. Zheng, J. Fan, G.D. Stucky, J. Am. Chem. Soc. 128 (2006) 6550.

[8] A. Courty, J. Richardi, P.-A. Albouy, M.-P. Pileni, Chem. Mater. 23 (2011) 4186.

[9] M. Rycenga, C.M. Cobley, J. Zeng, W. Li, C.H. Moran, Q. Zhang, D. Qin, Y. Xia, Chem.

Rev. 111 (2011) 3669.

[10] C.R. Bealing, W.J. Baumgardner, J.J. Choi, T. Hanrath, R.G. Hennig, ACS Nano 6 (2012) 2118 2127.

[11] J. Romann, J. Wei, M.-P. Pileni, J. Phys. Chem. C 119 (2015) 11094-11099.

[12] J. Wei, N. Schaeffer, M.-P. Pileni, J. Phys. Chem. B 118 (2014) 14070.

[13] M.D. Malinsky, K.L. Kelly, G.C. Schatz, R.P. Van Duyne, J. Am. Chem. Soc. 123 (2001) 1471.

[14] N. Aguilera-Porta, M. Calatayud, C. Salzemann, C. Petit, J. Phys. Chem. C 118 (2014) 9290.

[15] C. Salzemann, C. Petit, Langmuir 28 (2012) 4835.

[16] J. Xiao, L. Qi, Nanoscale 3 (2011) 1383-1396.

[17] C.Sanchez-Sanchez, N. Orozco, J.P.Holgado, S.K.Beaumont, G.Kyriakou, D.J.Watson, A.R.

Gonzalez-Elipe, L. Feria, J. Fernandez Sanz, R.M. Lambert, J. Am. Chem. Soc. 137 (2015) 940.

[18] D. Torres, N. Lopez, F. Illas, R.M. Lambert, J. Am. Chem. Soc. 127 (2005) 10774.

[19] P. Ferrin, S. Kandoi, A.U. Nilekar, M. Mavrikakis, Surf. Sci. 606 (2012) 679-689.

[20] M. Yu, H. Ascolani, G. Zampieri, D.P. Woodruff, C.J. Satterley, R.G. Jones, V.R. Dhanak, J. Phys. Chem. C 111 (2007) 10904-10914.

[21] M. Yu, D.P. Woodruff, N. Bovet, C.J. Satterley, K. Lovelock, R.G. Jones, V. Dhanak, J. Phys. Chem. B 110 (2006) 2164-2170.

[22] M. Yu, D.P. Woodruff, C.J. Satterley, R.G. Jones, V.R. Dhanak, J. Phys. Chem. C 111 (2007) 10040-10048.

[23] P.C. Rusu, G. Giovannetti, G. Brocks, J. Phys. Chem. C 111 (2007) 14448.

[24] D. Torres, P. Carro, R.C. Salvarezza, F. Illas, Phys. Rev. Lett. 97 (2006) 226103.

[25] L.A. Soria, G. Zampieri, M.L. Martiarena, J. Phys. Chem. C 115 (2011) 9587.

[26] Y. Wang, J.G. Solano Canchaya, W. Dong, M. Alcamí, H.F. Busnengo, F. Martín, J. Phys.

Chem. A 118 (2014) 4138.

[27] Y. Wang, J.G. Solano-Canchaya, M. Alcamí, H.F. Busnengo, F. Martín, J. Am. Chem. Soc. 134 (2012) 13224.

[28] O. Alexiadis, V.A. Harmandaris, V.G. Mavrantzas, L.D. Site, J. Phys. Chem. C 111 (2007) 6380.

[29] G. Kresse, J. Hafner, Phys. Rev. B 47 (1993) 558.

[30] G. Kresse, J. Hafner, Phys. Rev. B 49 (1994) 14251.

[31] P.E. Blochl, Phys. Rev. B 50 (1994) 17953-17979.

[32] G. Kresse, J. Joubert, Phys. Rev. B 59 (1999) 1758-1775.

[33] M.K. Rana, H.S. Koh, J. Hwang, D.J. Siegel, J. Phys. Chem. C 116 (2012) 16957. 
[34] K. Berland, P. Hyldgaard, Phys. Rev. B 87 (2013) 205421.

[35] J. Klimeš, D.R. Bowler, A. Michaelides, Phys. Rev. B 83 (2011) 195131.

[36] G. Graziano, J. Klimes, F. Fernandez-Alonso, A. Michaelides, J. Phys. Condens. Matter. 24

(2012) 424216.

[37] H.J. Monkhorst, J.D. Pack, Phys. Rev. B 13 (1976) 5188.

[38] J.P. Perdew, K. Burke, M. Ernzerhof, Phys. Rev. Lett. 77 (1996) 3865-3868.

[39] S. Grimme, J. Comp. Chem. 27 (2006) 1787.

[40] S. Grimme, J. Antony, S. Ehrlich, H. Krieg, J. Chem. Phys. 132 (2010) 154104.

[41] H. Yildirim, T. Greber, A. Kara, J. Phys. Chem. C 117 (2013) 20572.

[42] G. Henkelman, G. Jóhannesson, H. Jónsson, Methods for finding saddle points and minimum energy paths, in: S.D. Schwartz (Ed.), Progress on Theoretical Chemistry and Physics, Kluwer Academic Publishers 2000, p. 269.

[43] H. Henkelmann, H. Jónsson, J. Chem. Phys. 111 (1999) 7010.

[44] J.C. Love, L.A. Estroff, J.K. Kriebel, R.G. Nuzzo, G.M. Whitesides, Chem. Rev. 105 (2005) 1103.

[45] M.J. Frisch, G.W. Trucks, H.B. Schlegel, G.E. Scuseria, M.A. Robb, J.R. Cheeseman, G. Scalmani, V. Barone, B. Mennucci, G.A. Petersson, H. Nakatsuji, M. Caricato, X. Li, H.P. Hratchian, A.F. Izmaylov, J. Bloino, G. Zheng, J.L. Sonnenberg, M. Hada, M. Ehara, K. Toyota, R. Fukuda, J. Hasegawa, M. Ishida, T. Nakajima, Y. Honda, O. Kitao, H. Nakai, T. Vreven, J.A. Montgomery Jr., J.E. Peralta, F.O. Ogliaro, M.J. Bearpark, J. Heyd, E.N.Brothers, K.N. Kudin, V.N. Staroverov, R. Kobayashi, J. Normand, K. Raghavachari,

A.P. Rendell, J.C. Burant, S.S. Iyengar, J. Tomasi, M. Cossi, N. Rega, N.J. Millam, M. Klene, J.E. Knox, J.B. Cross, V. Bakken, C. Adamo, J. Jaramillo, R. Gomperts, R.E. Stratmann, O. Yazyev, A.J. Austin, R. Cammi, C. Pomelli, J.W. Ochterski, R.L. Martin, K. Morokuma, V.G. Zakrzewski, G.A. Voth, P. Salvador, J.J. Dannenberg, S. Dapprich, A.D. Daniels, Ã.d.n. Farkas, J.B. Foresman, J.V. Ortiz, J. Cioslowski, D.J. Fox, Gaussian 09, Gaussian, Inc., Wallingford, CT, USA, 2009.

[46] D.Karhanek,T.Bucko,J.Hafner,J.Phys.Condens.Matter22(2010)265005.

[47] R.A. Boto, J. Contreras-García, M. Calatayud, Comput. Theor. Chem. 1053 (2015) 322.

[48] F. Tielens, E. Santos, J. Phys. Chem. C 114 (2010) 9444-9452.

[49] R.F.W. Bader, Atoms in Molecules - A Quantum Theory, Oxford University Press, Oxford, 1990.

[50] D.S. Kosov, P.L.A. Popelier, J. Chem. Phys. 113 (2000) 3969.

[51] K.E. Laidig, R.F.W. Bader, J. Chem. Phys. 93 (1990) 7213.

[52] D. Myers, Surfactant Science and Technology, Wiley, 2005.

[53] N.B. Luque, E. Santos, Langmuir 28 (2012) 11472. 


\section{Supporting information}

Tests to validate the method

\begin{tabular}{|c|c|c|c|c|}
\hline parameters methods & PBE & PBE + D2 & optPBE & experimental \\
\hline $\mathrm{a}(\AA)$ & 4.16 & 4.12 & 4.15 & 4.09 \\
\hline $\mathrm{E}_{\mathrm{coh}}(\mathrm{eV})$ & 4.65 & 3.25 & 2.73 & 2.95 \\
\hline
\end{tabular}

Table S1. Lattice constant and cohesive energies obtained from PBE, PBE+D2 and optPBE methods for bulk Ag fcc system.

\begin{tabular}{|c|c|c|c|c|}
\hline $\begin{array}{l}\text { Monkhorst-Pack } \\
\text { scheme }\end{array}$ & $\begin{array}{c}\text { Lattice constant } \\
(\AA)\end{array}$ & $\begin{array}{l}\mathrm{E}_{\text {atom }} \\
(\mathrm{eV})\end{array}$ & $\begin{array}{c}\mathrm{E}_{\text {bulk }} \\
(\mathrm{eV})\end{array}$ & $\begin{array}{c}\mathrm{E}_{\text {cohesive }} \\
(\mathrm{eV})\end{array}$ \\
\hline $10 \times 10 \times 10$ & 4.15 & 3.33 & 2.30 & 2.76 \\
\hline $7 \times 7 \times 7$ & 4.15 & 3.33 & 2.31 & 2.76 \\
\hline $5 \times 5 \times 5$ & 4.15 & 3.33 & 2.38 & 2.74 \\
\hline $1 \times 1 \times 1$ & 4.15 & 3.33 & 8.75 & 1.14 \\
\hline
\end{tabular}

Table S2. K-points convergence test for the bulk fcc silver with the optPBE functional.

\section{Bader charges}

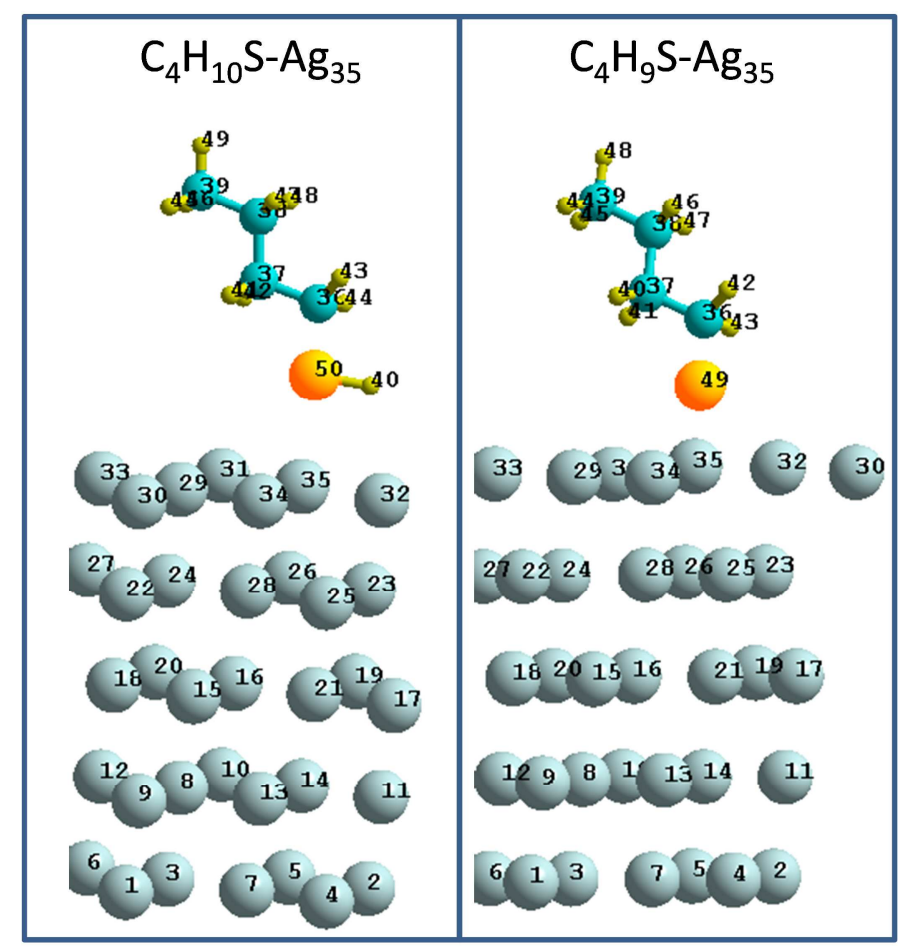




\begin{tabular}{|c|c|c|c|c|c|c|}
\hline $\begin{array}{l}\text { atom } \\
\#\end{array}$ & $\begin{array}{l}\text { bare slab } \\
\mathrm{Ag}\end{array}$ & $\begin{array}{l}\text { thiol } \\
\text { gas-phase }\end{array}$ & $\begin{array}{l}\text { thiol } \\
\text { RSH }\end{array}$ & $\begin{array}{l}\text { TS } \\
\text { RS-H }\end{array}$ & $\begin{array}{l}\text { thiolate } \\
\mathrm{RS}+\mathrm{H}\end{array}$ & $\begin{array}{l}\text { thiolate } \\
\text { no H } \\
\text { RS } \\
\end{array}$ \\
\hline 1 & -0.019 & & -0.017 & -0.018 & -0.018 & -0.018 \\
\hline 2 & -0.019 & & -0.021 & -0.012 & -0.015 & -0.015 \\
\hline 3 & -0.019 & & -0.017 & -0.020 & -0.021 & -0.020 \\
\hline 4 & -0.018 & & -0.018 & -0.024 & -0.026 & -0.021 \\
\hline 5 & -0.018 & & -0.019 & -0.020 & -0.016 & -0.019 \\
\hline 6 & -0.019 & & -0.018 & -0.017 & -0.015 & -0.020 \\
\hline 7 & -0.019 & & -0.022 & -0.022 & -0.018 & -0.019 \\
\hline 8 & 0.020 & & 0.019 & 0.015 & 0.012 & 0.017 \\
\hline 9 & 0.020 & & 0.020 & 0.015 & 0.014 & 0.016 \\
\hline 10 & 0.019 & & 0.018 & 0.020 & 0.017 & 0.015 \\
\hline 11 & 0.020 & & 0.020 & 0.019 & 0.021 & 0.019 \\
\hline 12 & 0.020 & & 0.019 & 0.015 & 0.014 & 0.016 \\
\hline 13 & 0.020 & & 0.019 & 0.019 & 0.021 & 0.020 \\
\hline 14 & 0.020 & & 0.019 & 0.019 & 0.017 & 0.020 \\
\hline 15 & -0.002 & & -0.002 & 0.002 & -0.001 & 0.001 \\
\hline 16 & -0.001 & & -0.001 & 0.003 & -0.001 & -0.002 \\
\hline 17 & -0.002 & & -0.002 & -0.001 & -0.002 & -0.001 \\
\hline 18 & -0.002 & & -0.001 & 0.000 & 0.000 & 0.000 \\
\hline 19 & -0.002 & & -0.002 & -0.004 & -0.002 & -0.003 \\
\hline 20 & -0.001 & & 0.000 & 0.002 & 0.002 & 0.002 \\
\hline 21 & -0.002 & & 0.000 & 0.005 & 0.006 & 0.007 \\
\hline 22 & 0.019 & & 0.017 & 0.027 & 0.019 & 0.024 \\
\hline 23 & 0.020 & & 0.017 & 0.016 & 0.006 & 0.011 \\
\hline 24 & 0.019 & & 0.020 & 0.015 & 0.020 & 0.021 \\
\hline 25 & 0.019 & & 0.016 & 0.015 & 0.015 & 0.013 \\
\hline 26 & 0.020 & & 0.021 & 0.015 & 0.008 & 0.015 \\
\hline 27 & 0.020 & & 0.018 & 0.017 & 0.017 & 0.024 \\
\hline 28 & 0.020 & & 0.018 & 0.010 & 0.015 & 0.008 \\
\hline 29 & -0.019 & & -0.034 & 0.003 & 0.008 & 0.011 \\
\hline 30 & -0.019 & & -0.035 & -0.005 & 0.068 & -0.017 \\
\hline 31 & -0.018 & & -0.030 & -0.018 & -0.005 & -0.005 \\
\hline 32 & -0.020 & & -0.029 & 0.075 & 0.081 & 0.083 \\
\hline 33 & -0.019 & & -0.037 & 0.008 & 0.074 & -0.001 \\
\hline 34 & -0.018 & & -0.012 & 0.039 & 0.081 & 0.070 \\
\hline 35 & -0.019 & & 0.036 & 0.107 & 0.145 & 0.082 \\
\hline 36 & & -0.058 & -0.058 & -0.061 & -0.039 & -0.042 \\
\hline 37 & & 0.050 & 0.049 & 0.065 & 0.035 & 0.060 \\
\hline 38 & & 0.033 & 0.027 & 0.059 & 0.041 & 0.055 \\
\hline 39 & & -0.002 & 0.027 & 0.053 & 0.028 & 0.038 \\
\hline 40 & & -0.024 & -0.005 & -0.057 & -0.209 & -0.002 \\
\hline 41 & & -0.005 & -0.010 & -0.008 & 0.004 & -0.011 \\
\hline 42 & & 0.013 & 0.010 & -0.012 & -0.004 & 0.029 \\
\hline
\end{tabular}




\begin{tabular}{|r|r|r|r|r|r|r|}
\hline 43 & & 0.020 & 0.030 & 0.030 & 0.024 & 0.025 \\
\hline 44 & & 0.026 & 0.031 & 0.033 & 0.035 & -0.017 \\
\hline 45 & & -0.008 & -0.012 & -0.014 & -0.008 & -0.009 \\
\hline 46 & & 0.000 & -0.019 & -0.015 & -0.016 & -0.031 \\
\hline 47 & & -0.004 & -0.022 & -0.026 & -0.017 & -0.012 \\
\hline 48 & & -0.025 & 0.000 & -0.020 & -0.010 & -0.017 \\
\hline 49 & & 0.007 & 0.001 & -0.024 & -0.001 & -0.399 \\
\hline 50 & & -0.023 & -0.031 & -0.323 & -0.403 & \\
\hline
\end{tabular}

Table S5: Bader charge of the atoms, in |e| for the systems calculated. 


\section{Structures used in the calculations}

\section{CONTCAR format in fractional coordinates}

Optimized butanethiol adsorbed on $\operatorname{Ag}(111) \sqrt{ } 7 \times \sqrt{ } 7$

\begin{tabular}{|c|c|c|c|c|c|c|}
\hline \multicolumn{7}{|c|}{$\begin{array}{l}\text { Molecular thiol on Ag V7V7 } \\
\quad 1.00730000000000\end{array}$} \\
\hline 7.7070660000000002 & \multicolumn{2}{|c|}{0.0000000000000000} & \multicolumn{3}{|c|}{0.0000000000000000} & \\
\hline-3.8535330000000001 & \multicolumn{2}{|c|}{6.6745150000000004} & \multicolumn{3}{|c|}{0.0000000000000000} & \\
\hline 0.0000000000000000 & \multirow{2}{*}{\multicolumn{2}{|c|}{0.0000000000000000}} & \multirow{2}{*}{\multicolumn{3}{|c|}{45.0000000000000000}} & \\
\hline \multicolumn{2}{|c|}{ Ag $\mathrm{CH} S$} & & & & & \\
\hline $35 \quad 4$ & \multicolumn{6}{|l|}{1} \\
\hline \multicolumn{7}{|l|}{ Selective dynamics } \\
\hline \multicolumn{7}{|l|}{ Direct } \\
\hline 0.0476190500000016 & 0.2380952500000006 & 0.18 & $\$ 1375799999980$ & $\mathrm{~F}$ & F & $\mathrm{F}$ \\
\hline 0.9047618499999999 & 0.5238094300000000 & 0.18 & 41375799999980 & $\mathrm{~F}$ & $\mathrm{~F}$ & $\mathrm{~F}$ \\
\hline 0.3333332600000034 & 0.6666665799999976 & 0.18 & 41375799999980 & $\mathrm{~F}$ & $\mathrm{~F}$ & $\mathrm{~F}$ \\
\hline 0.6190476299999972 & 0.0952381099999968 & 0.18 & $\$ 1375799999980$ & F & F & $\mathrm{F}$ \\
\hline 0.7619045900000003 & 0.8095236500000027 & 0.18 & 41375799999980 & $\mathrm{~F}$ & F & F \\
\hline 0.1904761199999996 & 0.9523808699999989 & 0.18 & $\$ 1375799999980$ & $\mathrm{~F}$ & F & F \\
\hline 0.4761904499999972 & 0.3809523899999974 & 0.18 & $\$ 1375799999980$ & $\mathrm{~F}$ & $F$ & $\mathrm{~F}$ \\
\hline 0.2857142399999972 & 0.4285713800000011 & 0.236 & 59920800000003 & $\mathrm{~F}$ & $\mathrm{~F}$ & F \\
\hline 0.0000000000000000 & 0.0000000000000000 & 0.236 & 59920800000003 & F & F & F \\
\hline 0.5714284700000007 & 0.8571427500000013 & 0.236 & 69920800000003 & F & F & F \\
\hline 0.8571427099999980 & 0.2857142599999989 & 0.236 & 59920800000003 & F & $\mathrm{F}$ & F \\
\hline 0.1428571100000013 & 0.7142856700000024 & 0.236 & 69920800000003 & F & $\mathrm{F}$ & F \\
\hline 0.4285714299999981 & 0.1428571599999984 & 0.236 & 69920800000003 & F & $\mathrm{F}$ & F \\
\hline 0.7142855900000029 & 0.5714285199999978 & 0.236 & 59920800000003 & F & $\mathrm{F}$ & F \\
\hline 0.2381271681673287 & 0.1929623486239490 & 0.28 & 95435598194765 & $\mathrm{~T}$ & $\mathrm{~T}$ & $\mathrm{~T}$ \\
\hline 0.5236365378275035 & 0.6213196231177992 & 0.28 & 95867202438260 & $\mathrm{~T}$ & $\mathrm{~T}$ & $\mathrm{~T}$ \\
\hline 0.8090805844288212 & 0.0492704172605807 & 0.28 & 96411462128707 & $\mathrm{~T}$ & $\mathrm{~T}$ & $\mathrm{~T}$ \\
\hline 0.0946396523508937 & 0.4783712468021754 & 0.28 & 95852886473159 & $\mathrm{~T}$ & $\mathrm{~T}$ & $\mathrm{~T}$ \\
\hline 0.9517409877403261 & 0.7639868489550929 & 0.28 & 95482075993305 & $\mathrm{~T}$ & $\mathrm{~T}$ & $\mathrm{~T}$ \\
\hline 0.3804076715454957 & 0.9067114028406077 & 0.28 & 95773872894727 & $\mathrm{~T}$ & $\mathrm{~T}$ & $\mathrm{~T}$ \\
\hline 0.6661465076709616 & 0.3354092751292561 & 0.28 & 95143357312868 & $\mathrm{~T}$ & $\mathrm{~T}$ & $\mathrm{~T}$ \\
\hline 0.0468749717275421 & 0.2424595233879601 & 0.342 & 20090384194341 & $\mathrm{~T}$ & $\mathrm{~T}$ & $\mathrm{~T}$ \\
\hline 0.9028029582812949 & 0.5284148304347612 & 0.342 & 24203469288055 & $\mathrm{~T}$ & $\mathrm{~T}$ & $\mathrm{~T}$ \\
\hline 0.3323940623002741 & 0.6713048238417116 & 0.342 & 22069597727739 & $\mathrm{~T}$ & $\mathrm{~T}$ & $\mathrm{~T}$ \\
\hline 0.6170288180647492 & 0.0994474570463971 & 0.342 & 21937192649549 & $\mathrm{~T}$ & $\mathrm{~T}$ & $\mathrm{~T}$ \\
\hline 0.7605957612326449 & 0.8136862178350136 & 0.342 & 26545421343745 & $\mathrm{~T}$ & $\mathrm{~T}$ & $\mathrm{~T}$ \\
\hline 0.1883743856301393 & 0.9569721811563605 & 0.342 & 21761751178053 & $\mathrm{~T}$ & $\mathrm{~T}$ & $\mathrm{~T}$ \\
\hline 0.4757887580019980 & 0.3862477853724085 & 0.342 & 25628624743935 & $\mathrm{~T}$ & $\mathrm{~T}$ & $\mathrm{~T}$ \\
\hline 0.2822020658563544 & 0.4339951330434378 & 0.395 & 51089209104242 & $\mathrm{~T}$ & $\mathrm{~T}$ & $\mathrm{~T}$ \\
\hline-0.0005819448940817 & 0.0061956803153473 & 0.39 & 55006237350275 & $\mathrm{~T}$ & $\mathrm{~T}$ & $\mathrm{~T}$ \\
\hline 0.5694298838267234 & 0.8623798402041295 & 0.395 & 54199119973310 & $\mathrm{~T}$ & $\mathrm{~T}$ & $\mathrm{~T}$ \\
\hline 0.8562124776242399 & 0.2878157496386297 & 0.39 & 11837610219117 & $\mathrm{~T}$ & $\mathrm{~T}$ & $\mathrm{~T}$ \\
\hline 0.1429347198663677 & 0.7204427193517401 & 0.39 & 48846871080607 & $\mathrm{~T}$ & $\mathrm{~T}$ & $\mathrm{~T}$ \\
\hline 0.4252574225570746 & 0.1459631334705102 & 0.39 & 48383965557046 & $\mathrm{~T}$ & $\mathrm{~T}$ & $\mathrm{~T}$ \\
\hline 0.7127494748432532 & 0.5783798144358790 & 0.395 & 55211010867296 & $\mathrm{~T}$ & $\mathrm{~T}$ & $\mathrm{~T}$ \\
\hline 0.7623729630802825 & 0.5785371739496969 & 0.493 & 30740267883841 & $\mathrm{~T}$ & $\mathrm{~T}$ & $\mathrm{~T}$ \\
\hline 0.5830926189960611 & 0.5929095519288413 & 0.50 & 42261042316971 & $\mathrm{~T}$ & $\mathrm{~T}$ & $\mathrm{~T}$ \\
\hline 0.5908662183755561 & 0.6215493322928436 & $0.53^{7}$ & 78905534874184 & $\mathrm{~T}$ & $\mathrm{~T}$ & $\mathrm{~T}$ \\
\hline
\end{tabular}




\begin{tabular}{|lllllll|}
\hline 0.4174547689029450 & 0.6420084799899559 & 0.5499102727761964 & $\mathrm{~T}$ & $\mathrm{~T}$ & $\mathrm{~T}$ \\
0.8862618881336264 & 0.4739990221783245 & 0.4517987700870387 & $\mathrm{~T}$ & $\mathrm{~T}$ & $\mathrm{~T}$ \\
0.4435016263090721 & 0.4559484590458590 & 0.4984645511199960 & $\mathrm{~T}$ & $\mathrm{~T}$ & $\mathrm{~T}$ \\
0.5782167707330633 & 0.7163447826351769 & 0.4929353410843927 & $\mathrm{~T}$ & $\mathrm{~T}$ & $\mathrm{~T}$ \\
0.7966830251835288 & 0.4903347945040343 & 0.5084544498660980 & $\mathrm{~T}$ & $\mathrm{~T}$ & $\mathrm{~T}$ \\
0.8945651975869033 & 0.7267495265966941 & 0.4907491644536552 & $\mathrm{~T}$ & $\mathrm{~T}$ & $\mathrm{~T}$ \\
0.2737402514423390 & 0.5118711039974956 & 0.5438548729023907 & $\mathrm{~T}$ & $\mathrm{~T}$ & $\mathrm{~T}$ \\
0.4202618752525511 & 0.7751304922853767 & 0.5409248565794186 & $\mathrm{~T}$ & $\mathrm{~T}$ & $\mathrm{~T}$ \\
0.5905571536203272 & 0.4929009272003684 & 0.5483608261634904 & $\mathrm{~T}$ & $\mathrm{~T}$ & $\mathrm{~T}$ \\
0.7336977964962212 & 0.7535210802364020 & 0.5439960746528191 & $\mathrm{~T}$ & $\mathrm{~T}$ & $\mathrm{~T}$ \\
0.4229391199215114 & 0.6540100045153066 & 0.5740778408705042 & $\mathrm{~T}$ & $\mathrm{~T}$ & $\mathrm{~T}$ \\
0.7039006977178235 & 0.4494130882246311 & 0.4571375546525683 & $\mathrm{~T}$ & $\mathrm{~T}$ & $\mathrm{~T}$ \\
\hline
\end{tabular}

\section{Transition state for the $\mathrm{S}-\mathrm{H}$ bond break}

\begin{tabular}{|c|c|c|c|c|c|c|c|}
\hline \multicolumn{8}{|l|}{$\begin{array}{l}\mathrm{S}-\mathrm{H} \text { bond break } \\
1.00292000000000\end{array}$} \\
\hline \multicolumn{2}{|c|}{7.7407249159653801} & \multicolumn{2}{|c|}{0.0000000000000000} & \multicolumn{3}{|c|}{0.0000000000000000} & \\
\hline \multicolumn{2}{|c|}{-3.8703624579826901} & \multicolumn{2}{|c|}{6.7036642840904603} & \multicolumn{3}{|c|}{0.0000000000000000} & \\
\hline \multirow{2}{*}{\multicolumn{2}{|c|}{$\begin{array}{l}0.0000000000000000 \\
\text { Ag CH S }\end{array}$}} & \multirow{2}{*}{\multicolumn{2}{|c|}{0.0000000000000000}} & \multirow{2}{*}{\multicolumn{3}{|c|}{45.1965279384197984}} & \\
\hline & & & & & & & \\
\hline $35 \quad 4$ & 1 & & & & & & \\
\hline \multicolumn{8}{|l|}{ Selective dynamics } \\
\hline 0.0476190500000016 & 0.2 & 380952500000006 & 0.184 & 41375799999981 & $\mathrm{~F}$ & $\mathrm{~F}$ & $\mathrm{~F}$ \\
\hline 0.9047618499999998 & 0.5 & 238094300000000 & 0.184 & 41375799999981 & $\mathrm{~F}$ & $\mathrm{~F}$ & $\mathrm{~F}$ \\
\hline 0.3333332600000034 & 0.6 & 666665799999976 & 0.18 & 41375799999981 & F & F & $\mathrm{F}$ \\
\hline 0.6190476299999972 & 0.0 & 952381099999968 & 0.18 & 41375799999981 & F & F & $\mathrm{F}$ \\
\hline 0.7619045900000003 & $0 . \varepsilon$ & 095236500000027 & 0.18 & 41375799999981 & $\mathrm{~F}$ & $\mathrm{~F}$ & $\mathrm{~F}$ \\
\hline 0.1904761199999996 & 0. & 523808699999989 & 0.18 & 41375799999981 & $\mathrm{~F}$ & $\mathrm{~F}$ & $\mathrm{~F}$ \\
\hline 0.4761904499999972 & 0.3 & 809523899999974 & 0.18 & 41375799999981 & F & F & $\mathrm{F}$ \\
\hline 0.2857142399999972 & 0.4 & 285713800000011 & 0.23 & 69920800000003 & F & $\mathrm{F}$ & $\mathrm{F}$ \\
\hline 0.0000000000000000 & 0.0 & 000000000000000 & 0.23 & 69920800000003 & $\mathrm{~F}$ & F & $\mathrm{F}$ \\
\hline 0.5714284700000007 & $0 . \varepsilon$ & 571427500000013 & 0.23 & 69920800000003 & F & $\mathrm{F}$ & $\mathrm{F}$ \\
\hline 0.8571427099999980 & 0.2 & 857142599999989 & 0.23 & 69920800000003 & F & $\mathrm{F}$ & $\mathrm{F}$ \\
\hline 0.1428571100000013 & 0.7 & 142856700000024 & 0.23 & 69920800000003 & $\mathrm{~F}$ & F & $\mathrm{F}$ \\
\hline 0.4285714299999980 & 0.1 & 428571599999984 & 0.23 & 69920800000003 & F & $\mathrm{F}$ & $\mathrm{F}$ \\
\hline 0.7142855900000029 & 0.5 & 714285199999978 & 0.23 & 69920800000003 & F & $\mathrm{F}$ & $\mathrm{F}$ \\
\hline 0.2387338263874105 & 0.1 & 978215307898277 & 0.28 & 97443592426466 & F & $\mathrm{F}$ & $\mathrm{F}$ \\
\hline 0.5249026878726312 & 0.6 & 243374291689773 & 0.28 & 95475399488386 & F & $\mathrm{F}$ & $\mathrm{F}$ \\
\hline 0.8094629303220023 & 0. & 528936854789372 & 0.28 & 99602049752470 & F & $\mathrm{F}$ & $\mathrm{F}$ \\
\hline 0.0962901067103106 & 0.5 & 830542664807870 & 0.28 & 95618521151270 & F & $\mathrm{F}$ & $\mathrm{F}$ \\
\hline 0.9541106390548224 & 0.7 & 692271115727107 & 0.28 & 94805252273487 & F & $\mathrm{F}$ & $\mathrm{F}$ \\
\hline 0.3826547447847423 & 0. & 106418626860071 & 0.28 & 96439869374774 & F & $\mathrm{F}$ & $\mathrm{F}$ \\
\hline 0.6666600794144000 & 0.3 & 385383339572487 & 0.28 & 93917336684406 & F & $\mathrm{F}$ & $\mathrm{F}$ \\
\hline 0.0473569205577290 & 0.2 & 495339342394277 & 0.342 & 22180426689811 & F & $\mathrm{F}$ & $\mathrm{F}$ \\
\hline 0.9030114376093221 & 0.5 & 341036219257689 & 0.342 & 22171056817564 & F & $\mathrm{F}$ & $\mathrm{F}$ \\
\hline 0.3317875378771059 & 0.6 & 784738604401548 & 0.34 & 19464176493033 & $\mathrm{~F}$ & $\mathrm{~F}$ & $\mathrm{~F}$ \\
\hline 0.6211732867281985 & 0.1 & 100908185918019 & 0.34 & 27460015990254 & $\mathrm{~F}$ & $\mathrm{~F}$ & $\mathrm{~F}$ \\
\hline 0.7618812383217914 & $0 . \varepsilon$ & 170354418146809 & 0.34 & 24071780958532 & F & $\mathrm{F}$ & $\mathrm{F}$ \\
\hline 0.1929627121818297 & 0. & 645287328500485 & 0.34 & 20435020116862 & $\mathrm{~F}$ & $\mathrm{~F}$ & $\mathrm{~F}$ \\
\hline 0.4789225870242547 & 0.3 & 938813332827181 & 0.34 & 30118081706539 & F & $\mathrm{F}$ & $\mathrm{F}$ \\
\hline 0.2885584745101413 & 0.4 & 474089442613732 & 0.39 & 38020901721114 & F & $\mathrm{F}$ & $\mathrm{F}$ \\
\hline 0.0020679256964600 & 0. & 200878110912437 & 0.39 & 43461768182214 & $\mathrm{~F}$ & $\mathrm{~F}$ & $\mathrm{~F}$ \\
\hline 0.5671775269499797 & $0 . \varepsilon$ & 736701661979009 & 0.39 & 35134966475131 & F & $\mathrm{F}$ & $\mathrm{F}$ \\
\hline 0.8619110269966451 & 0.2 & 991041290280727 & 0.39 & 50781492541167 & F & $\mathrm{F}$ & $\mathrm{F}$ \\
\hline 0.1412511288556246 & 0.7 & 308112913451539 & 0.39 & 61741719104049 & $\mathrm{~F}$ & $\mathrm{~F}$ & $\mathrm{~F}$ \\
\hline
\end{tabular}




\begin{tabular}{|lllllll|}
\hline 0.4232849229103770 & 0.1549920289544755 & 0.3948563336915083 & $\mathrm{~F}$ & $\mathrm{~F}$ & $\mathrm{~F}$ \\
0.7155525361523352 & 0.5990638429035750 & 0.3967387255303269 & $\mathrm{~F}$ & $\mathrm{~F}$ & $\mathrm{~F}$ \\
0.7357420133976568 & 0.5356014172350347 & 0.4819492255501305 & $\mathrm{~F}$ & $\mathrm{~F}$ & $\mathrm{~F}$ \\
0.5668572820543332 & 0.5575030312721833 & 0.4954862004902790 & $\mathrm{~F}$ & $\mathrm{~F}$ & $\mathrm{~F}$ \\
0.6016974220023196 & 0.6139705198402829 & 0.5284150155390241 & $\mathrm{~F}$ & $\mathrm{~F}$ & $\mathrm{~F}$ \\
0.4371622590598934 & 0.6414124550614367 & 0.5422309936686643 & $\mathrm{~F}$ & $\mathrm{~F}$ & $\mathrm{~F}$ \\
0.9168142572762652 & 0.6031183742097445 & 0.4204620128012129 & $\mathrm{~T}$ & $\mathrm{~T}$ & $\mathrm{~T}$ \\
0.4249419211458799 & 0.4162730494100980 & 0.4930942784575943 & $\mathrm{~F}$ & $\mathrm{~F}$ & $\mathrm{~F}$ \\
0.5496646291804735 & 0.6705409245477433 & 0.4831684997706330 & $\mathrm{~F}$ & $\mathrm{~F}$ & $\mathrm{~F}$ \\
0.7749351268574076 & 0.4470938935113230 & 0.4965830763961638 & $\mathrm{~F}$ & $\mathrm{~F}$ & $\mathrm{~F}$ \\
0.8701492639291651 & 0.6816763803445487 & 0.4790180555694210 & $\mathrm{~F}$ & $\mathrm{~F}$ & $\mathrm{~F}$ \\
0.2905911603945194 & 0.5067929624884983 & 0.5394517326720409 & $\mathrm{~F}$ & $\mathrm{~F}$ & $\mathrm{~F}$ \\
0.4292240070055031 & 0.7658198961487909 & 0.5319641457604495 & $\mathrm{~F}$ & $\mathrm{~F}$ & $\mathrm{~F}$ \\
0.6136134175917836 & 0.4964708511815896 & 0.5404491237306930 & $\mathrm{~F}$ & $\mathrm{~F}$ & $\mathrm{~F}$ \\
0.7464553563520796 & 0.7515380276382009 & 0.5312914123548360 & $\mathrm{~F}$ & $\mathrm{~F}$ & $\mathrm{~F}$ \\
0.4618988131086480 & 0.6719316119302812 & 0.5659320408998848 & $\mathrm{~F}$ & $\mathrm{~F}$ & $\mathrm{~F}$ \\
0.6764471884812503 & 0.4039450837465849 & 0.4462776405759606 & $\mathrm{~T}$ & $\mathrm{~T}$ & $\mathrm{~T}$ \\
\hline
\end{tabular}

\section{Thiolate $+\mathrm{H}$}

\begin{tabular}{|c|c|c|c|c|c|c|c|}
\hline \multicolumn{8}{|l|}{ Thio. } \\
\hline \multicolumn{8}{|l|}{1.00000000000000} \\
\hline \multicolumn{2}{|c|}{7.76332799999999996} & \multicolumn{2}{|c|}{0.0000000000000000} & \multicolumn{4}{|c|}{0.0000000000000000} \\
\hline \multicolumn{2}{|c|}{-3.8816639999999998} & \multicolumn{2}{|c|}{6.7232390000000004} & \multicolumn{4}{|c|}{0.0000000000000000} \\
\hline \multicolumn{2}{|c|}{0.0000000000000000} & \multicolumn{2}{|c|}{0.0000000000000000} & \multicolumn{4}{|c|}{45.3285029999999978} \\
\hline \multicolumn{8}{|c|}{ Ag $\mathrm{CH} \quad \mathrm{S}$} \\
\hline \multirow{2}{*}{\multicolumn{8}{|c|}{ Selective dynamics }} \\
\hline & & & & & & & \\
\hline \multicolumn{8}{|l|}{ Direct } \\
\hline 0.0476190500000016 & 0.2 & 380952500000006 & 0.184 & 41375799999980 & $\mathrm{~F}$ & $\mathrm{~F}$ & $\mathrm{~F}$ \\
\hline 0.9047618499999999 & 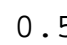 & 238094300000000 & 0.184 & 41375799999980 & $\mathrm{~F}$ & $\mathrm{~F}$ & $\mathrm{~F}$ \\
\hline 0.3333332600000034 & 0.6 & 666665799999976 & 0.184 & 41375799999980 & $\mathrm{~F}$ & $\mathrm{~F}$ & $\mathrm{~F}$ \\
\hline 0.6190476299999972 & 0.0 & 952381099999968 & 0.184 & 41375799999980 & $\mathrm{~F}$ & $\mathrm{~F}$ & $\mathrm{~F}$ \\
\hline 0.7619045900000003 & $0 . \varepsilon$ & 095236500000027 & 0.184 & 41375799999980 & $\mathrm{~F}$ & $\mathrm{~F}$ & $\mathrm{~F}$ \\
\hline 0.1904761199999996 & 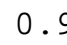 & 523808699999989 & 0.184 & 41375799999980 & $\mathrm{~F}$ & $\mathrm{~F}$ & $\mathrm{~F}$ \\
\hline 0.4761904499999972 & 0.3 & 809523899999974 & 0.184 & 41375799999980 & $\mathrm{~F}$ & $\mathrm{~F}$ & $\mathrm{~F}$ \\
\hline 0.2857142399999972 & 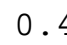 & 285713800000011 & 0.236 & 69920800000003 & $\mathrm{~F}$ & $\mathrm{~F}$ & $\mathrm{~F}$ \\
\hline 0.0000000000000000 & 0.0 & 000000000000000 & 0.236 & 69920800000003 & $\mathrm{~F}$ & $\mathrm{~F}$ & $\mathrm{~F}$ \\
\hline 0.5714284700000007 & $0 . \varepsilon$ & 571427500000013 & 0.236 & 69920800000003 & $\mathrm{~F}$ & $\mathrm{~F}$ & $\mathrm{~F}$ \\
\hline 0.8571427099999980 & 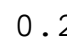 & 857142599999989 & 0.236 & 69920800000003 & $\mathrm{~F}$ & $\mathrm{~F}$ & $\mathrm{~F}$ \\
\hline 0.1428571100000013 & 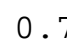 & 142856700000024 & 0.236 & 69920800000003 & $\mathrm{~F}$ & $\mathrm{~F}$ & $\mathrm{~F}$ \\
\hline 0.4285714299999981 & 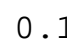 & 428571599999984 & 0.236 & 69920800000003 & $\mathrm{~F}$ & $\mathrm{~F}$ & $\mathrm{~F}$ \\
\hline 0.7142855900000029 & 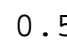 & 714285199999978 & 0.236 & 69920800000003 & $\mathrm{~F}$ & $\mathrm{~F}$ & $\mathrm{~F}$ \\
\hline 0.2385081470217079 & $0.1 \quad r(x-1$ & 997508487709125 & 0.290 & 01763274186034 & $\mathrm{~T}$ & $\mathrm{~T}$ & $\mathrm{~T}$ \\
\hline 0.5244414374812537 & 0.6 & 263222188102232 & 0.290 & 00170761540365 & $\mathrm{~T}$ & $\mathrm{~T}$ & $\mathrm{~T}$ \\
\hline 0.8108094143400395 & 0.0 & 547213729725614 & 0.290 & 05286653778165 & $\mathrm{~T}$ & $\mathrm{~T}$ & $\mathrm{~T}$ \\
\hline 0.0970876480322586 & 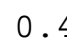 & 840940131838494 & 0.290 & 02810377437398 & $\mathrm{~T}$ & $\mathrm{~T}$ & $\mathrm{~T}$ \\
\hline 0.9542755980235899 & 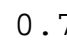 & 694418960063584 & 0.290 & 01598829465757 & $\mathrm{~T}$ & $\mathrm{~T}$ & $\mathrm{~T}$ \\
\hline 0.3837408805039951 & 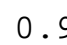 & 128339544435525 & 0.289 & 98833370875822 & $\mathrm{~T}$ & $\mathrm{~T}$ & $\mathrm{~T}$ \\
\hline 0.6679039226838732 & 0.3 & 396451839737910 & 0.289 & 99761750794340 & $\mathrm{~T}$ & $\mathrm{~T}$ & $\mathrm{~T}$ \\
\hline 0.0464540766955379 & 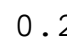 & 515649279262136 & 0.344 & 43987929498330 & $\mathrm{~T}$ & $\mathrm{~T}$ & $\mathrm{~T}$ \\
\hline 0.9051453908616017 & 0.5 & 381423899081379 & 0.343 & 38445566558527 & $\mathrm{~T}$ & $\mathrm{~T}$ & T \\
\hline 0.3323746072113286 & 0.6 & 829673497571217 & 0.343 & 31836174700067 & $\mathrm{~T}$ & $\mathrm{~T}$ & T \\
\hline 0.6236040800693404 & 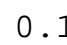 & 148392875927793 & 0.344 & 40185301763873 & $\mathrm{~T}$ & $\mathrm{~T}$ & T \\
\hline 0.7618630894490326 & $0 . \varepsilon$ & 200402708809136 & 0.343 & 34569594666356 & $\mathrm{~T}$ & $\mathrm{~T}$ & T \\
\hline 0.1953676344387478 & 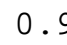 & 705431531848449 & 0.342 & 24258462864641 & $\mathrm{~T}$ & $\mathrm{~T}$ & T \\
\hline 0.4814027566351328 & 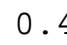 & 001020498022849 & 0.343 & 37607353485274 & $\mathrm{~T}$ & $\mathrm{~T}$ & T \\
\hline 0.2865525457852388 & 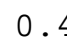 & 544708038397637 & 0.395 & 55598142565527 & $\mathrm{~T}$ & $\mathrm{~T}$ & T \\
\hline-0.0013238924321703 & 0.0 & 269977045107404 & 0.396 & 69911818687850 & $\mathrm{~T}$ & $\mathrm{~T}$ & T \\
\hline 0.5688685379028919 & & 796057084091174 & 0.395 & 53371093657771 & $\mathrm{~T}$ & $\mathrm{~T}$ & T \\
\hline
\end{tabular}




\begin{tabular}{|lllllll|}
\hline 0.8627645790887630 & 0.3086499347708719 & 0.3992504422286666 & $\mathrm{~T}$ & $\mathrm{~T}$ & $\mathrm{~T}$ \\
0.1495561949968690 & 0.7401108386897911 & 0.3969673727399475 & $\mathrm{~T}$ & $\mathrm{~T}$ & $\mathrm{~T}$ \\
0.4192787006141118 & 0.1634263511678689 & 0.3955019567166321 & $\mathrm{~T}$ & $\mathrm{~T}$ & $\mathrm{~T}$ \\
0.7159690334446149 & 0.6006582215344497 & 0.3997360646082305 & $\mathrm{~T}$ & $\mathrm{~T}$ & $\mathrm{~T}$ \\
0.7197514064593903 & 0.5111596502135057 & 0.4774157301493290 & $\mathrm{~T}$ & $\mathrm{~T}$ & $\mathrm{~T}$ \\
0.5563700019048006 & 0.5416305739283643 & 0.4914471741955841 & $\mathrm{~T}$ & $\mathrm{~T}$ & $\mathrm{~T}$ \\
0.6046310308831665 & 0.6081364107271892 & 0.5239816960396388 & $\mathrm{~T}$ & $\mathrm{~T}$ & $\mathrm{~T}$ \\
0.4472879840801278 & 0.6417384660328360 & 0.5392253060251795 & $\mathrm{~T}$ & $\mathrm{~T}$ & $\mathrm{~T}$ \\
0.9743824632458551 & 0.8090740975924371 & 0.4176603828427607 & $\mathrm{~T}$ & $\mathrm{~T}$ & $\mathrm{~T}$ \\
0.4125404710351766 & 0.4017209919680018 & 0.4905090463517409 & $\mathrm{~T}$ & $\mathrm{~T}$ & $\mathrm{~T}$ \\
0.5385486278008013 & 0.6530635921735606 & 0.4787492850503899 & $\mathrm{~T}$ & $\mathrm{~T}$ & $\mathrm{~T}$ \\
0.7636339693323639 & 0.4299495023905925 & 0.4927720323165239 & $\mathrm{~T}$ & $\mathrm{~T}$ & $\mathrm{~T}$ \\
0.8526056409306635 & 0.6546346562650176 & 0.4721662084871572 & $\mathrm{~T}$ & $\mathrm{~T}$ & $\mathrm{~T}$ \\
0.2987792404905447 & 0.5079345040910461 & 0.5379628611560880 & $\mathrm{~T}$ & $\mathrm{~T}$ & $\mathrm{~T}$ \\
0.4374839463744994 & 0.7654800656888141 & 0.5290963707297208 & $\mathrm{~T}$ & $\mathrm{~T}$ & $\mathrm{~T}$ \\
0.6199787889673304 & 0.4934501034391963 & 0.5362906427045033 & $\mathrm{~T}$ & $\mathrm{~T}$ & $\mathrm{~T}$ \\
0.7510543398157218 & 0.7458637773899198 & 0.5253915969192042 & $\mathrm{~T}$ & $\mathrm{~T}$ & $\mathrm{~T}$ \\
0.4829386066204177 & 0.6774419015171849 & 0.5627403980140355 & $\mathrm{~T}$ & $\mathrm{~T}$ & $\mathrm{~T}$ \\
0.6446586046743468 & 0.3554213346011486 & 0.4430166508007815 & $\mathrm{~T}$ & $\mathrm{~T}$ & $\mathrm{~T}$ \\
\hline
\end{tabular}




\section{Highlights}

- Buthanethiol adsorbs on quasi-hollow sites on $\operatorname{Ag}(111)$ regular surfaces

- Molecular and dissociated modes are isoenergetic

- Activation energy is calculated to be of $0.98 \mathrm{eV}$ for the perfect surface

- S-H bond break process induces significant adsorbate/substrate polarization 